\title{
Cough, chest pain and haemoptysis in a young nurse
}

\author{
A.F. Mobeireek
}

\section{Case report}

A 26 year old female nurse, of East African origin, presented with a 4 month history of intermittent cough, left-sided chest pain in the upper region, and mild haemoptysis for 2 days prior to admission. She gave a history of low grade intermittent fever and night sweats, and weight loss of about $3 \mathrm{~kg}$ over the previous 4 months, but denied anorexia. She had a long-standing history of intermittent breathlessness, cough, wheeze, runny nose and sneezing related to smells dating back to childhood. She was diagnosed to have mild asthma and allergic rhinitis, and responded to treatment with inhaled salbutamol and intranasal steroid sprays. She was, otherwise in excellent health, and was never admitted to hospital. She admitted possible contact with tuberculous patients 1 year earlier, when she was training as a student nurse at a chest hospital. She was a nonsmoker. Her family history was unremarkable.

a)

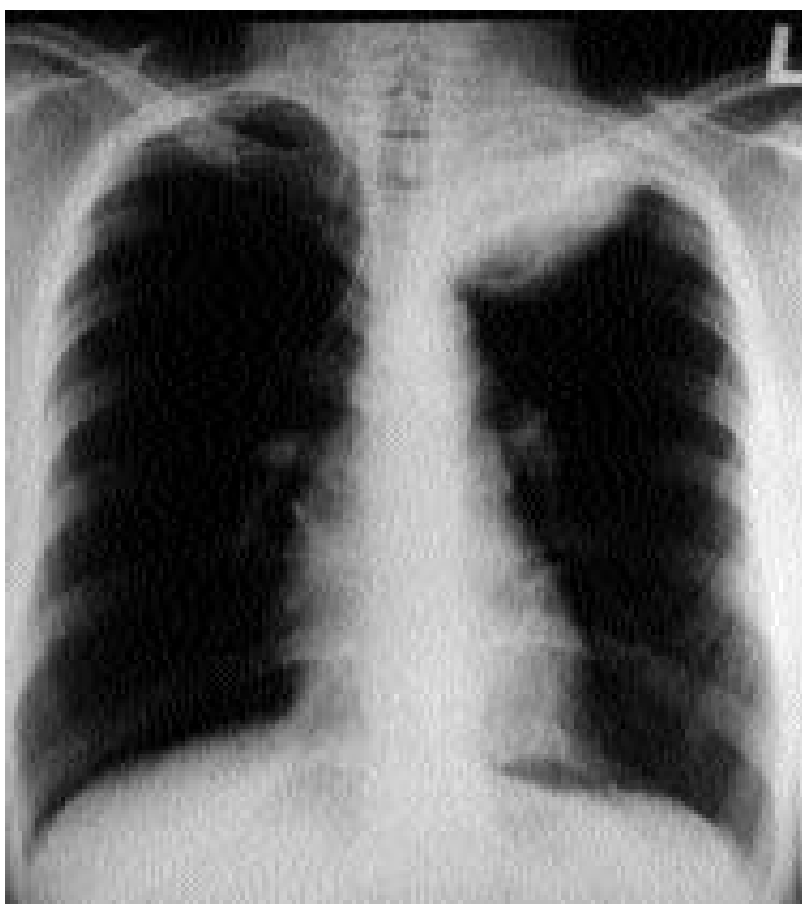

Fig. 1. - Chest radiograph. a) frontal; and b) lateral.
Physical examination revealed a well-built female with normal vital signs. The examination was unremarkable except for some dullness over the left apex.

Investigations showed a white blood cell (WBC) count of $4.63 \times 10^{9}$ cells $\cdot \mathrm{L}^{-1}$ (differential: neutrophils $59 \%$, lymphocytes $33 \%$, eosinophils 6\%). Spirometry showed a forced expiratory volume in one second (FEV1) of $2.68 \mathrm{~L}$ (103\% predicted) and forced vital capacity (FVC) of 3.03 L (110\% predicted). Sputum was negative for acid-fast organisms. Tuberculin skin test (5 units) was strongly positive $(30 \mathrm{~mm})$. Serum immunoglobulin E (IgE) was $341 \mathrm{IU} \cdot \mathrm{mL}^{-1}$. Other immunoglobulins were within the normal range. Standard skin-prick tests revealed mildto-moderate skin reactions $(3-5 \mathrm{~mm})$ to house dust mite, cat, moulds, Aspergillus clavatus and repens, Mucor and some pollens.

The chest radiographic images are shown in figure 1 . Fine needle aspiration of the visible mass revealed many giant cells, epitheloid cells and polymorphs, in keeping

b)

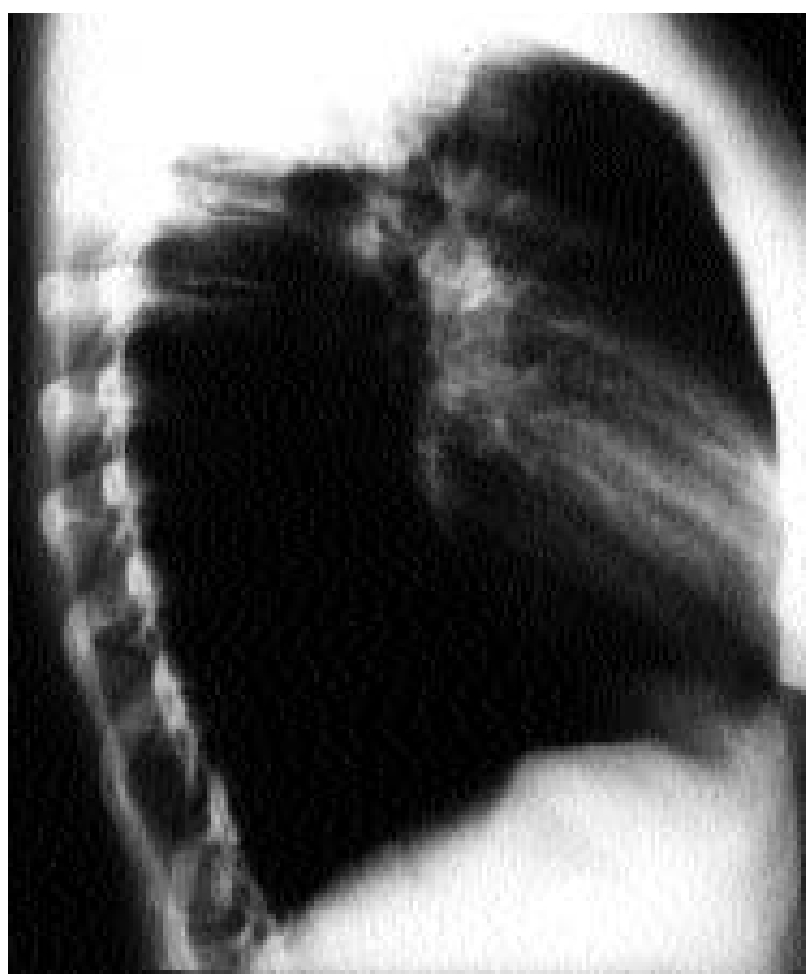


a)

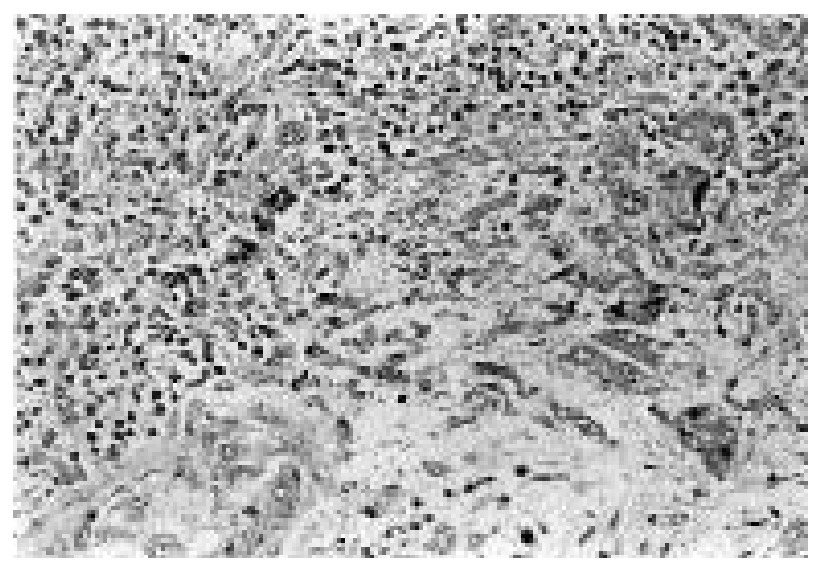

b)

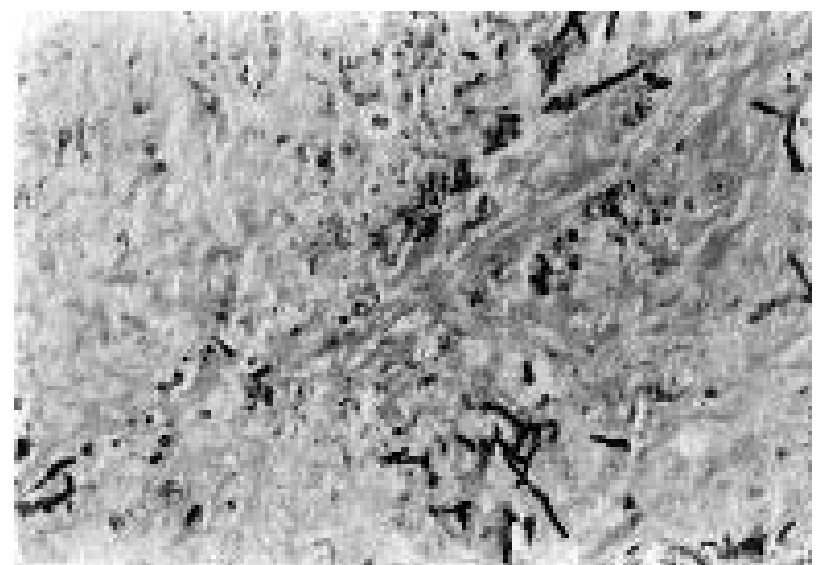

Fig. 2. - Microscopic view of the tumour: a) haemotoxylin and eosin stain; and b) Grocott's stain. (Original magnification $\times 100)$.

with granulamatous inflammation. Acid-fast stain and fungal smear were negative and no malignant cells were seen.

A provisional diagnosis of tuberculosis was made and the patient was started on a four anti-tuberculosis drug trial. Three months later, there were no clinical or radiological changes and she underwent thoractomy. A tumour was found, which was adherent to the chest wall and infiltrating the apex of the lung, $\mathrm{T}_{1}$ and $\mathrm{T}_{2}$ roots, the sympathetic plexus and the first two intercostal spaces. The mass was resected, and histopathological examination is presented in figure 2. 


\section{Interpretation of chest radiograph}

The frontal chest radiograph (fig. 1a) shows a wellcircumscribed oval mass in the left apical region. There was no evidence of calcification, cavitation, or erosion of the ribs or adjoining vertebral bodies. The lateral image (fig. 1b) shows a posterior location of the mass.

\section{Interpretation of the specimen}

Histopathological examination (fig. 2a) shows lung parenchyma effaced by acute and granulomatous inflammation admixed with neutrophilic infiltrate. Van Gieson's stain did not show any bronchioles. Grocott's stain (fig. 2b) shows Aspergillus hyphae.

\section{DIAGNOSIS: "Fungal granuloma" (Aspergillus flavus)}

\section{Clinical course}

The patient's postoperative recovery was uneventful. Antifungal therapy was not given because the mass was removed almost completely. She was kept under close follow-up for the following 2 years without relapse or occurrence of any unusual infections. Further tests for phagocyte function by chemiluminescence and nitroblue tetrazolium (NBT) slide test failed to show evidence of chronic granulmatous disease. Serology for human immunodeficiency virus (HIV) was also negative.

\section{Discussion}

Pulmonary aspergillosis continues to be a fascinating topic to clinicians of different specialities, in terms of the complex pathogenic mechanisms and the protean clinical manifestations. These range from immune-mediated (such as, allergic bronchopulmonary aspergillosis (ABPA) and hypersensitivity pneumonitis), infectious (acute and chronic forms) to symbiotic (aspergilloma). The list, however, goes beyond such simple classification to include many other unusual entities, for example, bronchocentric granulomatosis (BCG) [1], bronchiolitis obliterans [2], and an overlap of some of these conditions [3].

This patient presented with a lung mass, which pathologically appeared to be an Aspergillus granuloma (fig. 2 ). Although fungal granulomas in the lung secondary to Histoplasma, Coccidioides and Blastomyces are wellknown [4], Aspergillus, has rarely been implicated. Pulmonary infection with chest wall involvement by aspergillosis is unusual in the immunocompetent host and has been reported only in association with chronic granulomatous disease [5, 6] and previous tuberculosis [7]. The former was excluded in our patient by appropriate tests. It is conceivable, however, in view of her strongly positive tuberculin test that the disease started in an area damaged by tuberculous infection.
Aspergillus organisms have been associated with BCG in asthmatic patients [1]. A careful pathological examination showed no evidence of bronchocentric location, proximity to a pulmonary artery or tissue eosinophilia, essential features for this diagnosis. In addition, the patient had some criteria of ABPA, including asthma, positive skin-prick test, precipitins and a low titre of specific $\mathrm{IgE}$ for Aspergillus. Nonetheless, these were insufficient to make such a diagnosis [1].

Different species of aspergillus may predominate as pathogens, depending on the climatic and geographic factors [4, 8]. In this patient, of East African origin, Aspergillus flavus was isolated. This organism was shown to be one of the main pathogens responsible for pulmonary aspergillosis in that area [9]. A paranasal form also occurs mainly in Africa, and is again related to the same fungus [10].

In summary, this case illustrates an unusual manifestation of pulmonary aspergillosis. The diversity of pulmonary pathology caused by Aspergillus spp. makes it necessary to consider aspergillosis in patients with respiratory symptoms, particularly asthmatics.

Keywords: Aspergillus flavus, pulmonary granuloma.

Acknowledgements: The author is grateful to M. AlSohaibani for assistance in presenting the histopathology, and A. Al-Tweajri and R. Soliman for performing the chemiluminescence and NBT tests.

\section{References}

1. Sulavic SB. Bronchocentric granulomatosis and allergic bronchopulmonary aspergillosis. Clin Chest Med 1988; 9: 609-621.

2. Sieber SC, Cole SR, McNap JM, Shore R. Bronchiolitis associated with the finding of the fungus aspergillus: report of two cases. Conn Med 1994; 58: 13-17.

3. Katzenstein AL, Liebow AA, Friedman PJ. Bronchocentric granulomatosis, mucoid impaction and hypersensitivity reactions to fungi. Am Rev Respir Dis 1975; 111: 497-537.

4. Fraser RG, Pare JAP, Pare PD, Fraser RS, Genereux GP. Diagnosis of diseases of the chest. 3rd edn. Volume II. Mycotic and actinomycotic pleuropulmonary infection. Philadelphia, W.B. Saunders, 1989; p.940.

5. Kwon-Chung KJ, Bennett JE. Medical mycology: aspergillosis. Philadelphia, Lea \& Febiger, 1992; p.201.

6. Atman AR. Thoracic wall invasion secondary to pulmonary aspergillosis: a complication of chronic granulomatous disease of childhood. AJR 1977; 129: 140-142.

7. Hillerdal G. Pulmonary aspergillus infection invading the pleura. Thorax 1981; 36: 745-751.

8. Laham MN, Jeffery B, Carpenter JL. Frequency of clinical isolation and winter prevalence of different Aspergillus species at a large South Western Army Medical Center. Ann Allergy 1982; 48: 215-219.

9. Mahgoub ES, El-Hassan AM. Pulmonary aspergillosis caused by Aspergillus flavus. Thorax 1972; 27: 33-37.

10. Gumaa SA, Mahgoub ES, Hay RJ. Postoperative response of paranasal Aspergillus granuloma to itraconazole. Trans $R$ Soc Trop Med Hyg 1992; 86: 93-94. 